\title{
Ginsenoside $\mathrm{Rh} 2$ attenuates allergic airway inflammation by modulating nuclear factor- $\kappa B$ activation in a murine model of asthma
}

\author{
LIANG CHANG LI ${ }^{1 *}$, HONG MEI PIAO ${ }^{2 *}$, MING YU ZHENG ${ }^{3}$, \\ ZHEN HUA LIN $^{4}$, YUN HO CHOI ${ }^{5}$ and GUANG HAI YAN ${ }^{1}$ \\ ${ }^{1}$ Department of Anatomy, Histology and Embryology, Yanbian University School of Basic Medical Sciences, \\ Yanbian, Jilin 133002; ${ }^{2}$ Department of Respiratory Medicine, Yanbian University, Yanbian, Jilin 133000; \\ ${ }^{3}$ College of Pharmacy, Yanbian University, Yanbian, Jilin 133002; ${ }^{4}$ Department of Pathology, \\ Yanbian University School of Basic Medical Sciences, Yanbian, Jilin 133000, P.R. China; \\ ${ }^{5}$ Department of Anatomy, Medical School, Institute for Medical Sciences, Chonbuk National University, \\ Jeonju, Jeonbuk 561-756, Republic of Korea
}

Received October 22, 2014; Accepted July 21, 2015

DOI: $10.3892 / \mathrm{mmr} .2015 .4272$

\begin{abstract}
Allergic asthma is a chronic inflammatory disease that is regulated by coordination of T-helper type 2 cell cytokines and inflammatory signaling molecules. Ginsenoside Rh2 (G-Rh2) is an active component of ginseng with anti-inflammatory and anti-tumor effects. The aim of the present study was to determine the inhibitory effects of G-Rh2 on allergic airway inflammation in a murine model of asthma, in which mice develop the following pathophysiological features of asthma: Increased abundance of inflammatory cells; increased levels of interleukin-4 (IL-4), IL-5 and IL-13; decreased abundance of interferon gamma in the bronchoalveolar lavage fluid and lung tissue; increased total and ovalbumin (OVA)-specific immunoglobulin E ( $\operatorname{IgE})$ levels in the serum; increased airway hyperresponsiveness (AHR); and activation of nuclear factor kappa B (NF- $\mathrm{B})$ in lung tissue. In the asthmatic mice, administration of G-Rh2 markedly reduced peribronchiolar inflammation, recruitment of airway inflammatory cells, cytokine production, total and OVA-specific IgE levels and AHR. G-Rh2 administration inhibited NF- $\mathrm{NB}$ activation and p38 mitogen-activated protein kinase (MAPK) phosphorylation induced by OVA inhalation. These results suggested that G-Rh2 attenuates
\end{abstract}

Correspondence to: Dr Guang Hai Yan, Department of Anatomy, Histology and Embryology, Yanbian University School of Basic Medical Sciences, 977 Gongyuan Road, Yanji, Yanbian, Jilin 133002, P.R. China

E-mail: ghyan@ybu.edu.cn

*Contributed equally

Key words: ginsenoside Rh2, asthma, nuclear factor-kappa B, airway inflammation, $\mathrm{T}$ helper cell type 2 cytokines allergic airway inflammation by regulating $\mathrm{NF}-\kappa \mathrm{B}$ activation and p38 MAPK phosphorylation. The present study identified the molecular mechanisms of action of G-Rh2, which supported the potential use of G-Rh2 to prevent and/or treat asthma and other airway inflammatory disorders.

\section{Introduction}

Asthma, one of the most prevalent diseases worldwide, is a chronic inflammatory disease of the airways that is characterized by airway inflammation, airway hyperresponsiveness (AHR) and reversible airway obstruction. The pathological features of allergic asthma include inflammatory cell infiltration, edema, mast cell activation, denudation of the airway epithelium and collagen deposition (1). Asthma is closely associated with imbalances in T-helper cell type 1 (Th1)/Th2 abundance due to their distinct cytokine profiles $(2,3)$. Th2-specific cytokines, including interleukin (IL)-4, IL-5 and IL-13, are important mediators of humoral immune responses that induce immunoglobulin (Ig)E production and recruit eosinophils to the airways. Furthermore, Th2 cytokines that induce histamine and leukotriene release are associated with AHR (4,5). Th1 cytokines, including interferon gamma (IFN- $\gamma$ ) and IL-12, are involved in the mediation of the cellular immune response, and these cytokines restrain the development of asthma by acting in opposition to Th2-mediated immune responses and reducing IgE synthesis (6). Disease states occur when the dynamic balance of Th1/Th2 cell abundance and activation is disturbed. In recent years, increasing research interest has been focused on the inhibition of Th2 cell activation and the modulation of the Th1/Th2 equilibrium to prevent and treat asthma (7).

Nuclear factor kappa B (NF- $\mathrm{B})$, a well-studied transcriptional factor that has numerous important functions in cell signaling, also has a pivotal role in airway remodeling in asthma $(8,9)$. Cytokines and other factors that are triggered as part of inflammatory processes activate $\mathrm{NF}-\kappa \mathrm{B}$ via 
several signaling pathways, leading to a signaling cascade that amplifies inflammation. (8) Several studies have associated $\mathrm{NF}-\kappa \mathrm{B}$ overactivation with airway remodeling (10). The p38 mitogen-activated protein kinases (MAPKs) represent a point of convergence for multiple signaling processes that are activated in inflammation and that affect a diverse range of signaling events that mediate inflammatory processes $(11,12)$. Signaling via the p38 MAPK pathway regulates numerous pro-inflammatory transcription factors, such as activator protein 1 and $\mathrm{NF}-\kappa \mathrm{B}(13-15)$.

Ginseng, the root of Panax ginseng C.A. Meyer, has been used for millennia in traditional Asian medicine for preventive and therapeutic purposes due to its diverse biological effects $(16,17)$. Ginsenosides are the major bioactive constituents of ginseng (18-20). Ginsenoside Rh2 (G-Rh2) is a rare ginsenoside with a dammarane skeleton that is found only in red ginseng; however, G-Rh2 can be synthesized from easily available protopanaxadiol-type ginsenosides, which are similar to G-Rh2, with the exception of an additional glucose molecule at the C-3 position (21). G-Rh2 produces remarkable anti-proliferative (22) and pro-apoptotic effects (23), and prevents metabolic disorders, including obesity, via the $5^{\prime}$ adenosine monophosphate-activated protein kinase (AMPK) signaling pathway. Furthermore, total saponins and G-Rh2 showed a potential therapeutic effect against inflammation-mediated neuronal degeneration (24). Although numerous studies have investigated the underlying mechanisms of the anti-cancer activity of G-Rh2, the anti-inflammatory potential of G-Rh2 has not been well established, and the involvement of MAPK signaling and NF- $\mathrm{BB}$ in its effects have not been fully elucidated. Therefore, the present study investigated the mechanism of action of G-Rh2 in the context of MAPK and $\mathrm{NF}-\kappa \mathrm{B}$ signaling, which are known to regulate the inflammatory response, using an in vivo mouse model of allergic airway inflammation in asthma. The results of the present study provided insight into asthma prevention and treatment.

\section{Materials and methods}

Animals and experimental protocols. Forty-two specific pathogen-free (SPF), inbred, female BALB/c mice (age, seven weeks; weight, 20-30 g) were obtained from the in-house animal production facility of the Yanbian University Health Science Center (Yanji, China). The mice were maintained in an animal facility under a 12-h light/dark cycle at $22^{\circ} \mathrm{C}$ in standard laboratory conditions for one week prior to the experiments. Water and a standard diet were provided ad libitum. The experiments were performed in compliance with the guidelines approved by the Institutional Animal Care and Use Committee of the Yanbian University School of Medical Sciences (Yanji, China). Mice were immunized intraperitoneally with $10 \mu \mathrm{g}$ ovalbumin (OVA; chicken egg albumin; Sigma-Aldrich, St. Louis, MO, USA) with $1.0 \mathrm{mg}$ aluminum hydroxide adjuvant (Imject ${ }^{\circledR}$ Alum; Pierce, Rockford, IL, USA). A booster injection of $10 \mu \mathrm{g}$ OVA plus $1.0 \mathrm{mg}$ aluminum hydroxide adjuvant was given 10 days after the initial OVA/adjuvant treatment. From days 17-19, the immunized mice were challenged by exposure to an aerosol of $1 \%$ OVA in phosphate-buffered saline (PBS) for $20 \mathrm{~min}$. Bronchoprovocation was performed in a vented plastic chamber $(18 \times 14 \times 8 \mathrm{~cm})$ that was adapted for mice. Aerosol particles of 3-5 mm in diameter were created using an ultrasonic nebulizer (NE-U12; Omron, Tokyo, Japan), directed into the plastic chamber and vented to a fume hood. Each group consisted of seven animals. The saline-treated mice that served as controls were exposed to aerosolized saline. G-Rh2 (98\% purity) was purchased from the National Institute for the Control of Pharmaceutical and Biological Products (Beijing, China) and dissolved in $0.1 \%$ dimethyl sulfoxide (DMSO). The animals received G-Rh2 (50 or $100 \mathrm{mg} / \mathrm{kg}$ ) or dexamethasone (DXM; $0.5 \mathrm{mg} / \mathrm{kg}$ ) by oral gavage at $24-\mathrm{h}$ intervals, beginning $1 \mathrm{~h}$ prior to the first provocation (challenge), on days 17-19.

Harvest of bronchoalveolar lavage (BAL) fluids and cytospin preparations. Immediately following the assessment of airway responsiveness, mice were anesthetized by intraperitoneal injection of pentobarbital $(50 \mathrm{mg} / \mathrm{kg}$; Wuhan Boster Biological Technology, Ltd., Wuhan, China) and the trachea was cannulated while gently massaging the thorax, after which the lungs were lavaged with $0.7 \mathrm{ml}$ PBS. BAL fluid samples were collected and the number of cells in a $0.05-\mathrm{ml}$ aliquot was counted using a hemocytometer. The remaining samples were centrifuged at $200 \mathrm{x} \mathrm{g}$ for $10 \mathrm{~min}$ at $4^{\circ} \mathrm{C}$ (model $5424 \mathrm{R}$ centrifuge, Eppendorf-Netheler, Hamburg, Germany) and the supernatants were stored at $-70^{\circ} \mathrm{C}$ for analyses of IL-4, IL-5, IL-13 and IFN- $\gamma$ levels. Cell pellets were re-suspended in PBS and cytospin preparations (Cytospin 3; Shandon Life Sciences, Astmor, UK) of the BAL cells were stained with Diff-Quik solution (International Reagents, Kobe, Japan). Two independent, blinded investigators counted the cells using a microscope. Approximately 400 cells were counted in each of four different random fields of view (CX31 microscope; Olympus Corporation, Tokyo, Japan). Inter-investigator variation was $<5 \%$. The results were expressed as the mean value of the cell counts determined by the two investigators.

Determination of cytokines in BAL fluids. IL-4, IL-5, IL-13 and IFN- $\gamma$ levels in BAL and IgE in serum were determined using ELISA kits for mice. The IL-4 kit was obtained from Invitrogen Life Technologies (Carlsbad, CA, USA) and IL-5, IL-13, IFN- $\gamma$ and IgE kits were obtained from R\&D Systems Inc. (Minneapolis, MN, USA). The enzyme immunoassays were performed according to the manufacturer's instructions.

Determination of total IgE and OVA-specific IgE in serum. Total IgE and OVA-specific IgE were measured by ELISA. Briefly, 96-well microtiter plates were coated overnight with an isotype-specific coating (total $\mathrm{IgE}$ ) and $10 \mathrm{mg} / \mathrm{ml}$ OVA in PBS-Tween 20 (OVA-specific IgE). After washing and blocking of the plates, the samples were incubated for $2 \mathrm{~h}$. Subsequently, the plates were washed and horseradish peroxidase-conjugated goat anti-mouse total IgE and OVA-specific IgE were added. After washing the samples four times in PBS-Tween-20 solution, $200 \mu \mathrm{l} o$-phenylenediamine dihydrochloride (Sigma-Aldrich) was added to each well. The plates were incubated for $10 \mathrm{~min}$ in the dark and absorbance was determined at $450 \mathrm{~nm}$ using a Bio-Rad 680 microplate ELISA reader (Bio-Rad Laboratories, Hercules, CA, USA). Total IgE and OVA-specific IgE concentrations were calculated from a 
standard curve that was generated using $250 \mathrm{ng} / \mathrm{ml}$ recombinant $\operatorname{IgE}$.

Histological examination of murine lung tissue. After BAL preparation, the lungs were resected, fixed with $4 \%$ paraformaldehyde and embedded in paraffin. Specimens were cut into $4-\mu \mathrm{m}$ sections using a Leica model 2165 rotary microtome (Leica Microsystems, Wetzlar, Germany). The microsections were stained with hematoxylin and eosin (Richard-Allan Scientific, Kalamazoo, MI, USA) and examined under the CX31 microscope (magnification, x100).

Nuclear protein extractions for analysis of $N F-\kappa B$. Freshly isolated lung tissue samples were washed and lysed in two volumes of lysis buffer A $(50 \mathrm{mM}$ Tris- $\mathrm{HCl}, \mathrm{pH} 7.5,1 \mathrm{M}$ EDTA, $10 \%$ glycerol, $0.5 \mathrm{mM}$ dithiothreitol, $5 \mathrm{mM} \mathrm{MgCl}$, $1 \mathrm{mM}$ phenylmethanesulfonylfluoride (PMSF) and protease inhibitor cocktails) for $5 \mathrm{~min}$ at $4^{\circ} \mathrm{C}$. The resulting suspension was centrifuged at $1,000 \mathrm{xg}$ for $15 \mathrm{~min}$ at $4^{\circ} \mathrm{C}$. The supernatant fraction was incubated on ice for $10 \mathrm{~min}$ and centrifuged at $100,000 \mathrm{x}$ g for $1 \mathrm{~h}$ at $4^{\circ} \mathrm{C}$ to obtain cytosolic protein extracts. The pelleted nuclei were re-suspended in buffer $\mathrm{B}\left(1.3 \mathrm{M}\right.$ sucrose, $1.0 \mathrm{mM} \mathrm{MgCl}_{2}, 10 \mathrm{mM}$ potassium phosphate buffer, $\mathrm{pH}$ 6.8) and centrifuged at 1,000 $\mathrm{xg}$ for $15 \mathrm{~min}$. The pellets were suspended in buffer B with a final sucrose concentration of $2.2 \mathrm{M}$ and centrifuged at $100,000 \mathrm{xg}$ for $1 \mathrm{~h}$. The resulting nuclear pellets were washed once with a solution containing $0.25 \mathrm{M}$ sucrose, $0.5 \mathrm{mM} \mathrm{MgCl}_{2}$ and $20 \mathrm{mM}$ Tris- $\mathrm{HCl}$ ( $\mathrm{pH} 7.2$ ), and centrifuged at 1,000 xg for $10 \mathrm{~min}$. The nuclear pellets were solubilized with a solution of $50 \mathrm{mM}$ Tris- $\mathrm{HCl}$ ( $\mathrm{pH} 7.2), 0.3 \mathrm{M}$ sucrose, $150 \mathrm{mM} \mathrm{NaCl}$, 2 mM EDTA, 20\% glycerol, 2\% Triton X-100, 2 mM PMSF and protease inhibitor cocktails, and the resulting mixture was kept on ice for $1 \mathrm{~h}$ with gentle stirring, after which it was centrifuged at $12,000 \mathrm{x} \mathrm{g}$ for $30 \mathrm{~min}$. The resulting soluble nuclear protein supernatant samples were used for western blot analysis.

Western blot analysis. Lung tissue samples were homogenized in the presence of protease inhibitors and protein concentrations were determined using the Bradford reagent (Bio-Rad Laboratories). Samples of protein from the lung homogenates (30 $\mu \mathrm{g}$ per lane) were subjected to $12 \%$ SDS-PAGE and transferred onto nitrocellulose membranes. Western blot analysis was performed using the following antibodies at a dilution of 1:1,000: Rabbit anti-mouse polyclonal antibodies against IL-5 (cat. no. sc-7887), p38 MAPK (cat. no. sc-535), phospho-p38 MAPK (cat. no. sc-101759), poly(adenosinediphosphate) ribose polymerase (PARP) (cat. no. sc-25780), NF-кB p65 (cat. no. sc-109), nuclear factor of kappa light polypeptide gene enhancer in B-cells

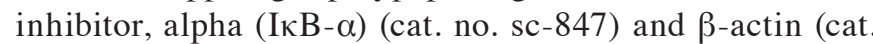
no. sc-130656) (all from Santa Cruz Biotechnology, Inc., Dallas, TX, USA) as well as IL-13 (cat. no. AF-413-NA; R\&D Systems) or IL-4 (cat. no. AAM36; Serotec, Oxford, $\mathrm{UK}$ ), or the goat anti-mouse polyclonal antibody IFN- $\gamma$ (cat. no. sc-9344; Calbiochem, San Diego, CA, USA). The binding of all the antibodies was detected using an ECL detection system (Amersham, Arlington Heights, IL, USA) according to the manufacturer's instructions.
Assessment of AHR. Airway responsiveness was measured two days after the last OVA challenge according to the method of Choi et al (25). Conscious unrestrained mice were placed in a barometric plethysmographic chamber (OCP3000; All Medicus, Seoul, Korea), and baseline readings were collected and averaged for $3 \mathrm{~min}$. Aerosolized methacholine (Mch; All Medicus) at increasing concentrations (from 2.5 to $50 \mathrm{mg} / \mathrm{ml}$ ) was nebulized through an inlet of the main chamber for $3 \mathrm{~min}$, and readings were taken and averaged for $3 \mathrm{~min}$ after each nebulization. The bronchopulmonary resistance was determined by calculating enhanced pauses (Penh) according to the manufacturer's protocol with the following equation:

$$
\text { Penh }=(T e / R T-1) \mathrm{x}(P E F / P I F)
$$

where $T e$ was the expiratory time, $R T$ was the relaxation time, $P E F$ was the peak expiratory flow and $P I F$ was the peak inspiratory flow. The results are expressed as the percentage increase in Penh over the baseline value after PBS challenge (taken as 100\%) following a challenge performed with each concentration of Mch.

Statistical analysis. Values are expressed as the mean \pm standard error of the mean. Statistical evaluation of the data was performed using analysis of variance, followed by Dunnett's post-hoc test. SPSS 13.0 software (SPSS, Inc., Chicago, IL, USA) was used to perform analyses and $\mathrm{P}<0.05$ was considered to indicate a statistically significant difference.

\section{Results}

G-Rh2 attenuates cellular changes in BAL fluids of OVA-induced asthmatic mice. In BAL fluid, the total cell number and the numbers of eosinophils, lymphocytes and neutrophils were significantly increased $24 \mathrm{~h}$ after OVA inhalation in comparison with those measured $24 \mathrm{~h}$ after saline inhalation (Fig. 1A). Of note, these effects of OVA inhalation were significantly reduced by administration of G-Rh2 or positive control DXM.

$G$-Rh2 attenuates pathological changes associated with OVA-induced asthma. Histological analyses revealed widespread perivascular and peribronchiolar inflammatory cell infiltrates, which are typical pathological features of asthma, in OVA-challenged mice, but these features were not found in control mice. OVA-exposed mice treated with G-Rh2 or DXM (Fig. 1B) showed significantly reduced inflammatory-cell infiltration in the peribronchiolar and perivascular regions in comparison with that in mice exposed to OVA only. These results suggested that G-Rh2 inhibits inflammatory-cell infiltration and attenuates antigen-induced airway inflammation.

G-Rh2 attenuates OVA-induced increases in $I L-4, I L-5$ and IL-13 protein levels in lung tissue and BAL fluid of mice. Western blot analysis revealed that IL-4, IL-5 and IL-13 protein levels in lung tissue were significantly increased $24 \mathrm{~h}$ after OVA inhalation in comparison with levels measured $24 \mathrm{~h}$ after saline inhalation. The OVA-induced increases in IL-4, IL-5 and IL-13 protein levels were significantly inhibited by 


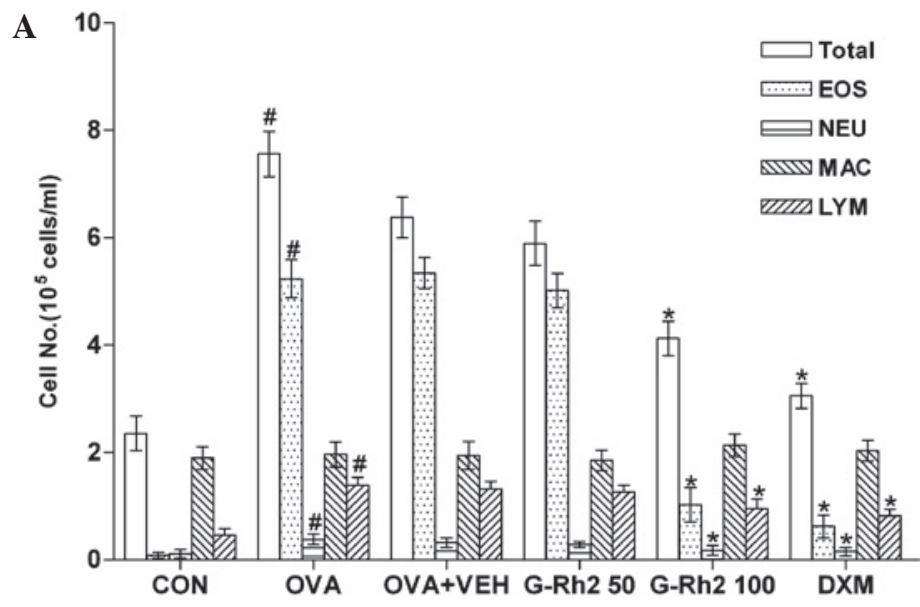

B
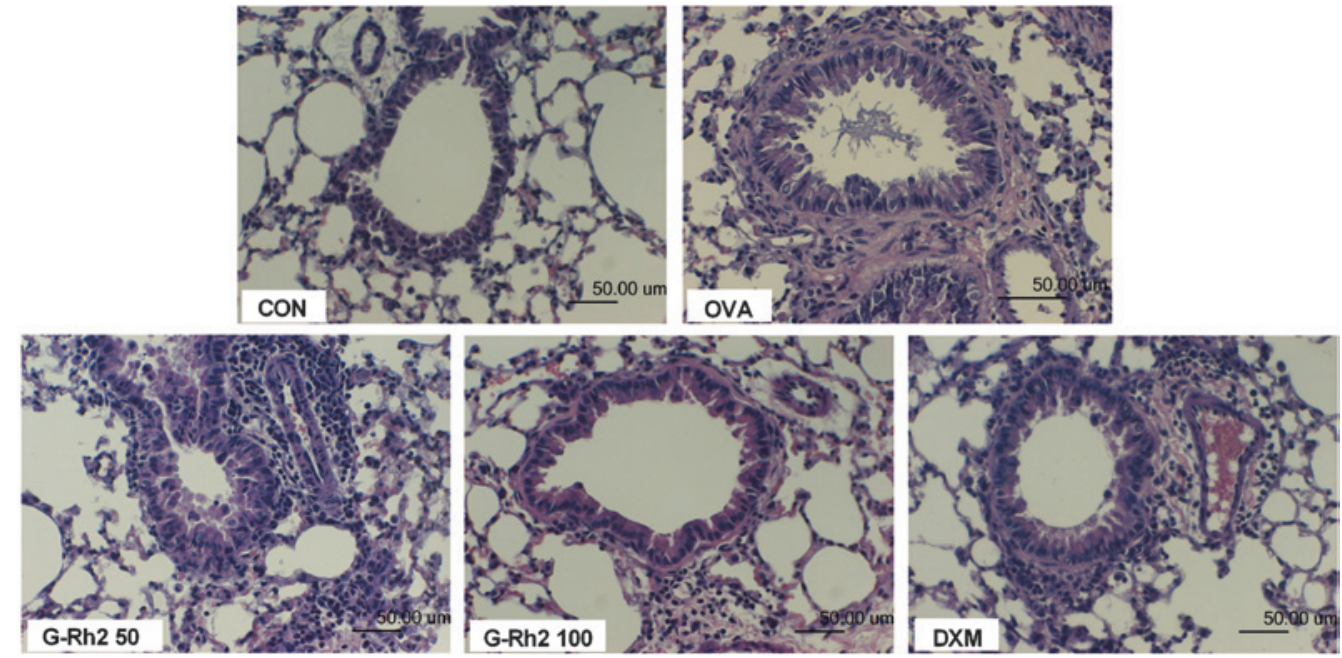

Figure 1. Effect of G-Rh2 on immune cell counts in BAL and pathological changes in the lung tissues of OVA-challenged mice. (A) Numbers of each counted cell type in BAL. Mice were orally administered G-Rh2 or DXM (positive control) daily for three consecutive days after the first OVA challenge. The effects of G-Rh2 and DXM on OVA challenge-induced changes in cell counts in BAL fluid were analyzed $24 \mathrm{~h}$ after the last OVA challenge. Results of five independent experiments ( 7 mice/group) are expressed as the mean \pm standard error of the mean. ${ }^{~} \mathrm{P}<0.05$ vs. control group; ${ }^{*} \mathrm{P}<0.05$ vs. OVA-challenged group. (B) Hematoxylin and eosin-stained sections of lung tissue (magnification, x200; scale bar, $50 \mu \mathrm{m}$ ). Paraffin-embedded lung sections were prepared $24 \mathrm{~h}$ after the last OVA challenge and stained with hematoxylin and eosin. Images are representative of five independent experiments. Groups: CON, saline-treated mice; OVA, OVA-challenged mice; OVA+VEH, OVA-challenged mice treated with the drug vehicle; G-Rh2 50, OVA-challenged mice treated with $50 \mathrm{mg} / \mathrm{kg}$ G-Rh2; G-Rh2 100, OVA-challenged mice treated with $100 \mathrm{mg} / \mathrm{kg} \mathrm{G}-\mathrm{Rh} 2$; DXM, OVA-challenged mice treated with $0.5 \mathrm{mg} / \mathrm{kg}$ DXM. EOS, eosinophil; NEU, neutrophil; MAC, macrophage; LYM, lymphocyte; G-Rh2, ginsenoside Rh2; BAL, bronchoalveolar lavage fluid; OVA, ovalbumin; VEH, vehicle; DXM, dexamethasone.
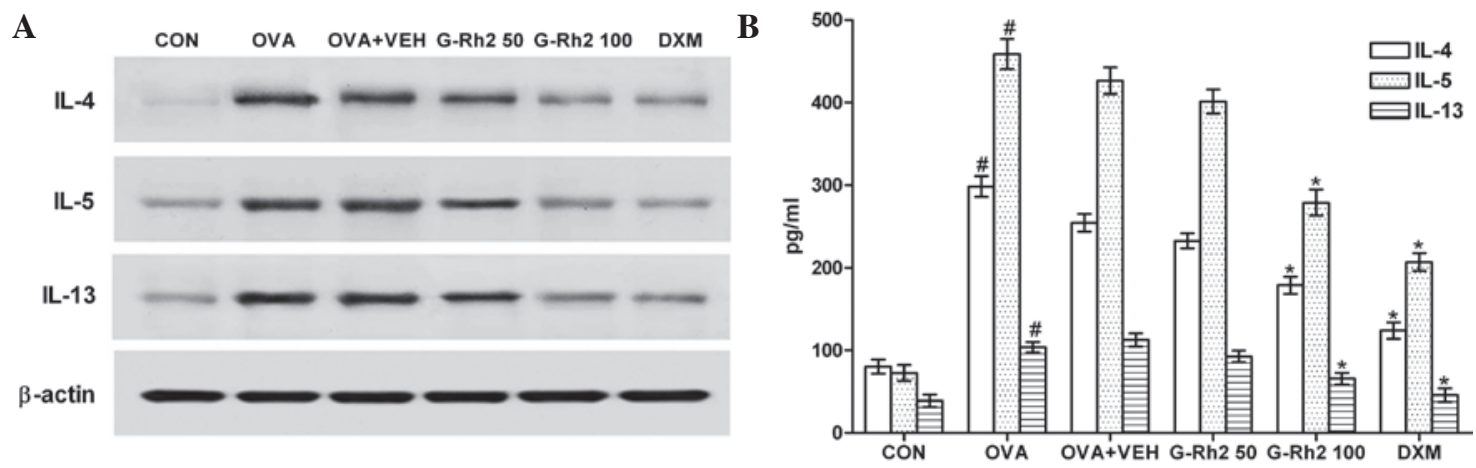

Figure 2. Assessment of T-helper type 2 cell cytokines in BAL fluid and lung tissue from OVA-challenged mice treated with ginsenoside Rh2. (A) Lung tissue was collected $24 \mathrm{~h}$ after the last OVA challenge and levels of IL-4, IL-5 and IL-13 were determined by western blot analysis. A representative immunoblot of five independent experiments is shown. (B) BAL fluid was collected $24 \mathrm{~h}$ after the last OVA challenge and levels of IL-4, IL-5 and IL-13 were quantified by ELISA. Results from five independent experiments ( 7 mice/group) are expressed as the mean \pm standard error of the mean. ${ }^{~} \mathrm{P}<0.05$ vs. control group; "P<0.05 vs. OVA-challenged group. Groups: CON, saline-treated mice; OVA, OVA-challenged mice; OVA+VEH, OVA-challenged mice treated with the drug vehicle; G-Rh2 50, OVA-challenged mice treated with $50 \mathrm{mg} / \mathrm{kg} \mathrm{G}-\mathrm{Rh} 2 ; \mathrm{G}-\mathrm{Rh} 2$ 100, OVA-challenged mice treated with $100 \mathrm{mg} / \mathrm{kg}$ G-Rh2; DXM, OVA-challenged mice treated with $0.5 \mathrm{mg} / \mathrm{kg}$ DXM. BAL, bronchoalveolar lavage; IL, interleukin; OVA, ovalbumin; VEH, vehicle; DXM, dexamethasone; G, ginsenoside. 

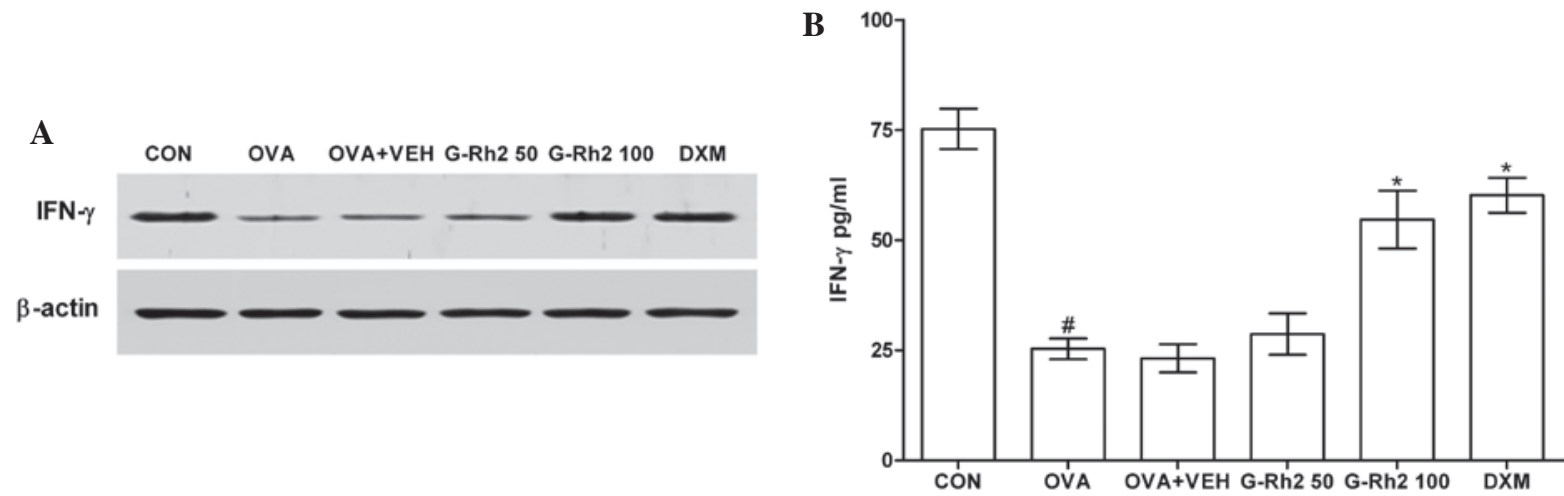

Figure 3. Assessment of T-helper type 1 cell cytokines in BAL fluid and lung tissues from OVA-challenged mice treated with ginsenoside Rh2. (A) Lung tissue was collected $24 \mathrm{~h}$ after the last OVA challenge and the abundance of IFN- $\gamma$ was measured by western blot analysis. A representative immunoblot of five independent experiments is shown. (B) BAL fluid was collected $24 \mathrm{~h}$ after the last OVA challenge and the abundance of IFN- $\gamma$ was quantified by ELISA. Results from five independent experiments ( 7 mice/group) are expressed as the mean \pm standard error of the mean. ${ }^{~} \mathrm{P}<0.05$ vs. control group; ${ }^{*} \mathrm{P}<0.05$ vs. OVA-challenged group. Groups: CON, saline-treated mice; OVA, OVA-challenged mice; OVA+VEH, OVA-challenged mice treated with the drug vehicle; G-Rh2 50, OVA-challenged mice treated with $50 \mathrm{mg} / \mathrm{kg}$ G-Rh2; G-Rh2 100, OVA-challenged mice treated with $100 \mathrm{mg} / \mathrm{kg}$ G-Rh2; DXM, OVA-challenged mice treated with $0.5 \mathrm{mg} / \mathrm{kg}$ dexamethasone. BAL, bronchoalveolar lavage; IL, interleukin; OVA, ovalbumin; VEH, vehicle; DXM, dexamethasone; IFN, interferon; G, ginsenoside.
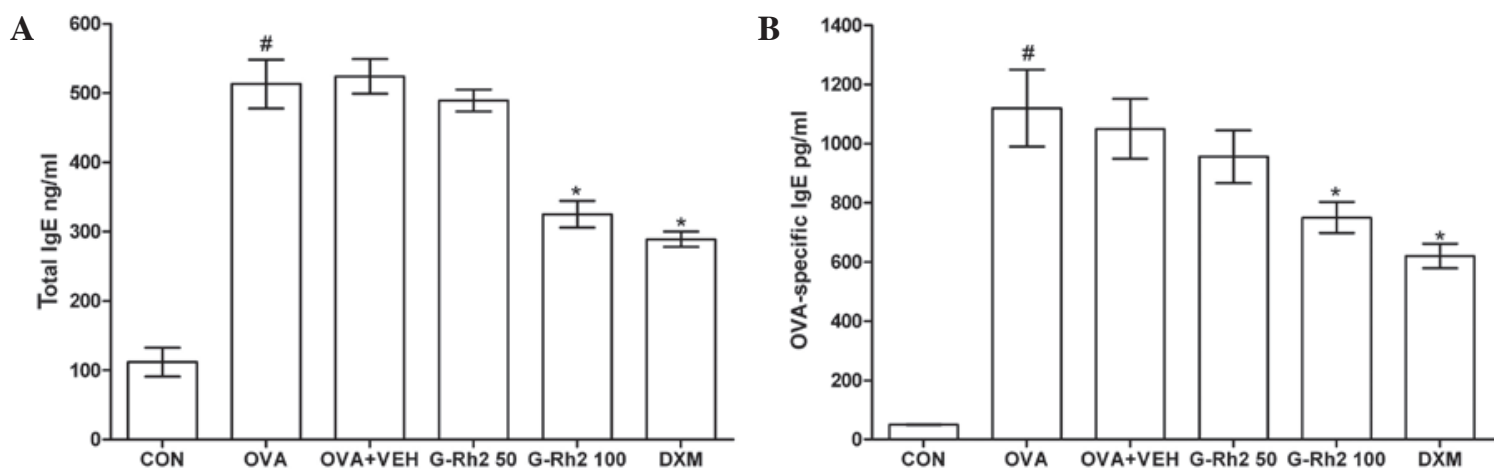

Figure 4. Effect of ginsenoside Rh2 on total IgE and OVA-specific IgE levels in serum from mice with OVA-induced asthma. (A) Total IgE abundance. (B) OVA-specific IgE abundance. Serum was collected $24 \mathrm{~h}$ after the last OVA challenge and IgE was quantified by ELISA. Results of five independent experiments ( 7 mice/group) are expressed as the mean \pm standard error of the mean. ${ }^{*} \mathrm{P}<0.05$ vs. control group; "P $<0.05$ vs. OVA-challenged group. Groups: CON, saline-treated mice; OVA, OVA-challenged mice; OVA+VEH, OVA-challenged mice treated with the drug vehicle; G-Rh2 50, OVA-challenged mice treated with $50 \mathrm{mg} / \mathrm{kg} \mathrm{G}-\mathrm{Rh} 2 ;$ G-Rh2 100, OVA-challenged mice treated with $100 \mathrm{mg} / \mathrm{kg} \mathrm{G}-\mathrm{Rh} 2 ; \mathrm{DXM}$, OVA-challenged mice treated with $0.5 \mathrm{mg} / \mathrm{kg}$ dexamethasone. IgE, immunoglobulin E; OVA, ovalbumin; VEH, vehicle; DXM, dexamethasone; G, ginsenoside.

administration of G-Rh2 or DXM (Fig. 2A). Consistent with these results, ELISAs revealed that protein levels of IL-4, IL-5 and IL-13 in BAL fluid were also significantly increased $24 \mathrm{~h}$ after OVA inhalation in comparison with levels measured $24 \mathrm{~h}$ after saline inhalation (Fig. 2B), and these changes in protein abundance were also significantly inhibited by administration of G-Rh2 or DXM.

$G-R h 2$ attenuates decreases in IFN- $\gamma$ protein levels in lung tissue and BAL fluid from mice with OVA-induced asthma. To determine the effect of G-Rh2 on the Th1 response, IFN- $\gamma$ abundance in lung tissue was assessed using western blot analysis. IFN- $\gamma$ abundance in OVA-challenged mice was reduced in comparison with that in control mice (Fig. 3A). However, administration of G-Rh2 or DXM inhibited OVA-induced reductions in IFN- $\gamma$ abundance. Similarly, ELISAs of BAL fluid showed that IFN- $\gamma$ protein abundance was significantly reduced in OVA-challenged mice in comparison with that of control mice (Fig. 3A), and pre-treatment with G-Rh2 or DXM inhibited this change in expression.
G-Rh2 attenuates increases in total IgE and OVA-specific $\mathrm{IgE}$ levels in serum of mice with OVA-induced asthma. The total IgE and OVA-specific IgE levels in each experimental group were determined by ELISA $24 \mathrm{~h}$ after the final OVA challenge. Total IgE and OVA-specific IgE levels in serum were significantly increased $24 \mathrm{~h}$ after OVA inhalation in comparison with levels measured $24 \mathrm{~h}$ after saline inhalation (Fig. 4). In comparison with the OVA-challenged group, increased total $\mathrm{IgE}$ and OVA-specific IgE levels in serum were significantly reduced in the groups treated with G-Rh2 or DXM.

$G$-Rh2 prevents OVA-induced NF- $\kappa B$ p65 translocation in lung tissue of mice by blocking of phosphorylation and degradation of $I \kappa B-\alpha$. Western blot analysis revealed that nuclear $\mathrm{NF}-\kappa \mathrm{B}$ p 65 abundance in the lung was increased $24 \mathrm{~h}$ after OVA inhalation in comparison with that in the control mice, and this effect was inhibited by administration of G-Rh2 or DXM. By contrast, cytosolic NF- $\kappa$ B p65 abundance was reduced $24 \mathrm{~h}$ after OVA inhalation in comparison with that 
A

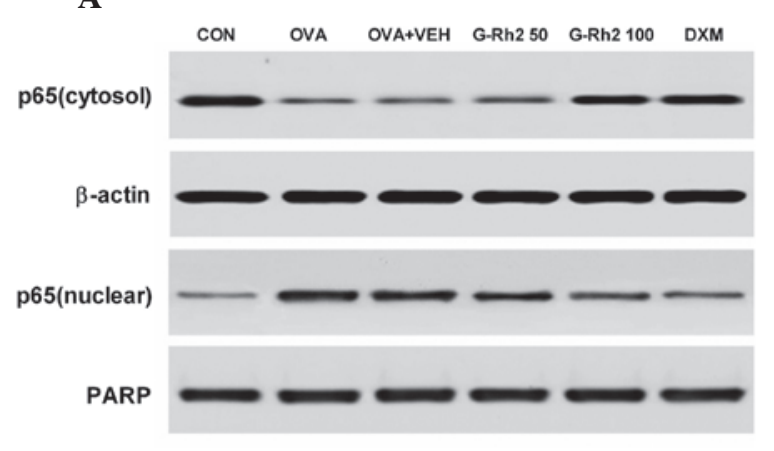

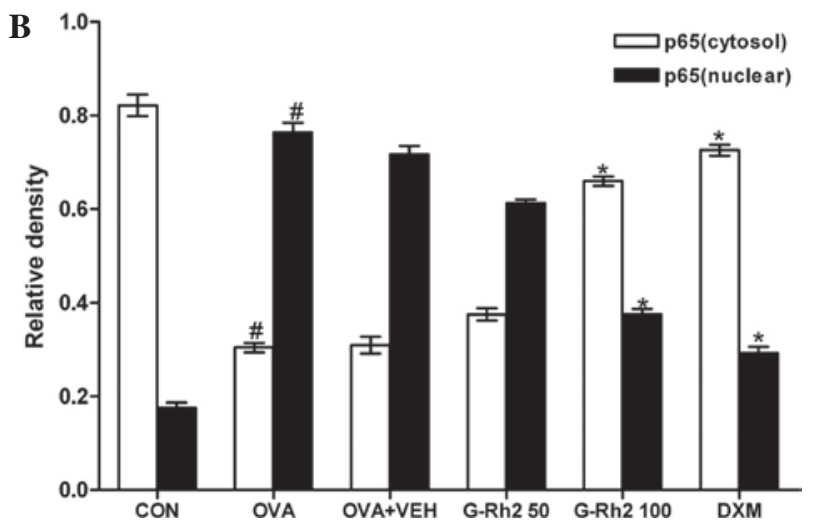

Figure 5. Effect of ginsenoside Rh2 on OVA challenge-induced NF- $\kappa \mathrm{B}$ activation. Mice were orally administered ginsenoside Rh2 or DXM daily for three consecutive days after the first OVA challenge. Lung homogenates were prepared $24 \mathrm{~h}$ after the last OVA challenge. Translocation of p65 to the nucleus was assessed by western blot. $\beta$-actin and PARP were used as internal controls. (A) An immunoblot representative of five independent experiments is shown. (B) Bands were quantified by densitometric analysis relative to $\beta$-actin or PARP. Results from five independent experiments ( 7 mice/group) are expressed as the mean \pm standard error of the mean. ${ }^{\#} \mathrm{P}<0.05$ vs. control group; ${ }^{*} \mathrm{P}<0.05$ vs. OVA-challenged group. Groups: CON, saline-treated mice; OVA, OVA-challenged mice; OVA+VEH, OVA-challenged mice treated with the drug vehicle; G-Rh2 50, OVA-challenged mice treated with 50 mg/kg G-Rh2; G-Rh2 100, OVA-challenged mice treated with $100 \mathrm{mg} / \mathrm{kg} \mathrm{G}-\mathrm{Rh} 2$; DXM, OVA-challenged mice treated with $0.5 \mathrm{mg} / \mathrm{kg}$ DXM. NF, nuclear factor; PARP, poly(adenosine diphosphate ribose) polymerase; OVA, ovalbumin; VEH, vehicle; DXM, dexamethasone; G, ginsenoside.
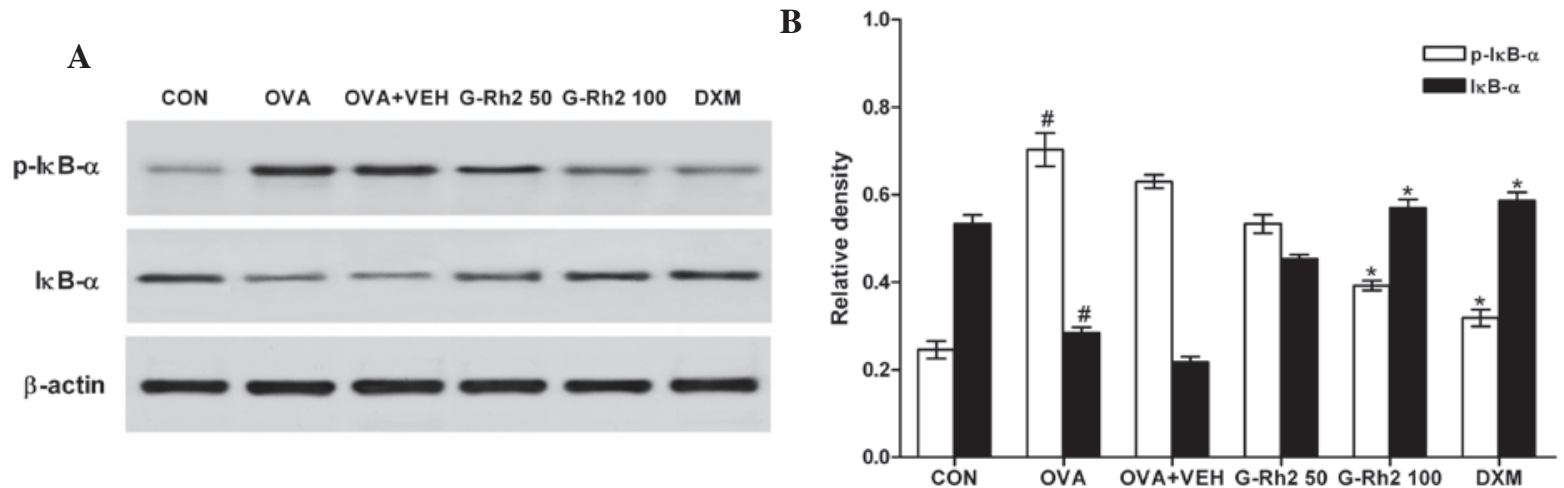

Figure 6. Effect of ginsenoside Rh2 on OVA challenge-induced phosphorylation of IкB- $\alpha$ in the cytoplasm. Mice were orally administered ginsenoside Rh2 or DXM daily for three consecutive days after the first OVA challenge. Lung homogenates were prepared $24 \mathrm{~h}$ after the last OVA challenge. I B- $\alpha$ phosphorylation and degradation in the cytoplasm were assessed by western blot analysis. $\beta$-actin was used as an internal control. (A) An immunoblot representative of five independent experiments is shown. (B) Bands were quantified by densitometric analysis compared to $\beta$-actin. Results from five independent experiments (7 mice/group) are expressed as the mean \pm standard error of the mean. ${ }^{\#} \mathrm{P}<0.05$ vs. control group; ${ }^{*} \mathrm{P}<0.05$ vs. OVA-challenged group. Groups: CON, saline-treated mice; OVA, OVA-challenged mice; OVA+VEH, OVA-challenged mice treated with the drug vehicle; G-Rh2 50, OVA-challenged mice treated with 50 mg/kg G-Rh2; G-Rh2 100, OVA-challenged mice treated with 100 mg/kg G-Rh2; DXM, OVA-challenged mice treated with 0.5 mg/kg DXM. p-IкB- $\alpha$, phosphorylated inhibitor of nuclear factor $\kappa \mathrm{B}$, alpha; OVA, ovalbumin; VEH, vehicle; DXM, dexamethasone; G, ginsenoside.

of the control mice (Fig. 5A and B), and this effect was also inhibited by administration of G-Rh2 or DXM. The effect of G-Rh2 on OVA-induced phosphorylation and degradation of I $\kappa$ B- $\alpha$ was studied to examine the molecular mechanisms by which G-Rh2 inhibits NF- $\mathrm{B}$ transcriptional activity. G-Rh2 significantly blocked OVA-induced phosphorylation and degradation of I $\mathrm{B}-\alpha$ (Fig. 6A and B). These results indicated that G-Rh2 prevents NF- $\kappa$ B translocation in OVA-challenged mice by blocking phosphorylation and degradation of $\mathrm{I} \kappa \mathrm{B}-\alpha$.

G-Rh2 inhibits OVA-induced p38 MAPK phosphorylation in lung tissue of mice. Western blot analysis was used to determine the phosphorylation/activation status of p38 MAPK, which is an upstream mediator of NF- $\mathrm{B}$ activation. Phospho-p38 protein abundance in the lung was increased $24 \mathrm{~h}$ after OVA inhalation in comparison with that of the control mice, and this effect was inhibited by administration of G-Rh2 or DXM
(Fig. 7A and B). However, no significant changes in p38 MAPK protein abundance were observed in any group.

$G-R h 2$ reduces methacholine-induced AHR in mice with OVA-induced asthma. The present study investigated the effect of G-Rh2 on the development of AHR in mice. Airway responsiveness (determined by calculating Penh) induced by methacholine inhalation was increased in OVA-challenged mice in comparison with that in control mice, and this effect was inhibited by administration of G-Rh2 or DXM, as shown in Fig. 8.

\section{Discussion}

Asthma is a chronic inflammatory disease of the airways that is characterized by infiltration of airway inflammatory cells and AHR to inhaled allergens and non-specific 


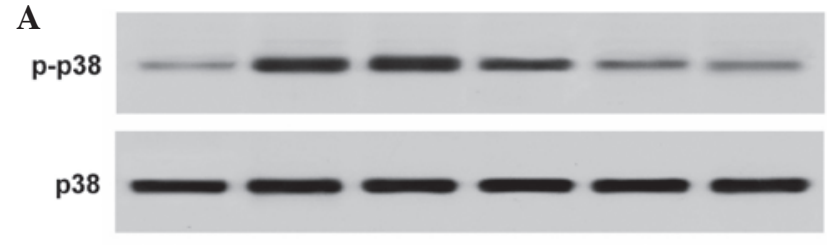

B

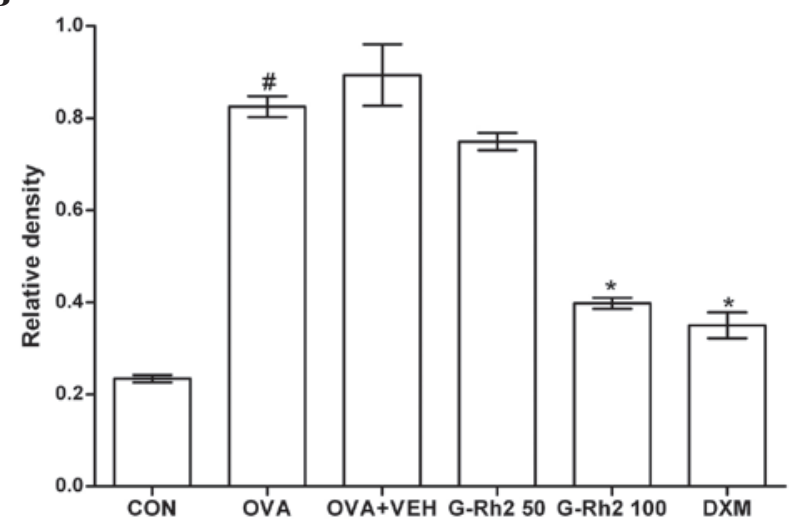

Figure 7. Effect of ginsenoside Rh2 on OVA challenge-induced p38 activation. Mice were orally administered ginsenoside Rh2 or DXM daily for three consecutive days after the first OVA challenge. Lung homogenates were prepared $24 \mathrm{~h}$ after the last OVA challenge and p38 phosphorylation was assessed by western blot. Total p38 was used as an internal control. (A) An immunoblot representative of five independent experiments is shown. (B) p-p38 bands were quantified by densitometric analysis compared to total p38. Results from five independent experiments ( 7 mice/group) are expressed as the mean \pm standard error of the mean. ${ }^{~} \mathrm{P}<0.05$ vs. control group; " $\mathrm{P}<0.05$ vs. OVA-challenged group. Groups: $\mathrm{CON}$, saline-treated mice; OVA, OVA-challenged mice; OVA+VEH, OVA-challenged mice treated with the drug vehicle; G-Rh2 50, OVA-challenged mice treated with $50 \mathrm{mg} / \mathrm{kg}$ G-Rh2; G-Rh2 100, OVA-challenged mice treated with $100 \mathrm{mg} / \mathrm{kg}$ G-Rh2; DXM, OVA-challenged mice treated with $0.5 \mathrm{mg} / \mathrm{kg}$ DXM. OVA, ovalbumin; VEH, vehicle; DXM, dexamethasone; G, ginsenoside; p, phosphorylated.

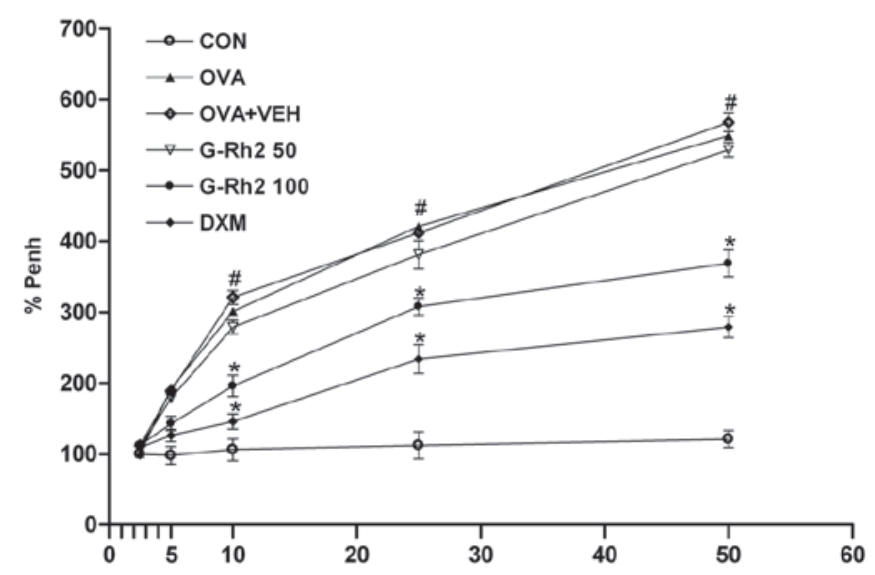

Figure 8. Effect of ginsenoside Rh2 on OVA challenge-induced airway hyperresponsiveness. All animals were nebulized with various concentrations of methacholine $(2.5,5,10,25$ or $50 \mathrm{mg} / \mathrm{ml})$ as a bronchoconstrictor. Values are expressed as the percentage increase in Penh over that of the saline-treated control group (which was set as $100 \%$ ). Results of five independent experiments ( 7 mice/group) are expressed as the mean \pm standard error of the mean. ${ }^{\#} \mathrm{P}<0.05$ vs. control group; ${ }^{*} \mathrm{P}<0.05$ vs. OVA-challenged group. Groups: CON, saline-treated mice; OVA, OVA-challenged mice; OVA+VEH, OVA-challenged mice treated with the drug vehicle; G-Rh2 50 , OVA-challenged mice treated with $50 \mathrm{mg} / \mathrm{kg}$ G-Rh2; G-Rh2 100 , OVA-challenged mice treated with $100 \mathrm{mg} / \mathrm{kg} \mathrm{G}-\mathrm{Rh} 2 ; \mathrm{DXM}$, OVA-challenged mice treated with $0.5 \mathrm{mg} / \mathrm{kg}$ DXM. OVA, ovalbumin; VEH, vehicle; DXM, dexamethasone; G, ginsenoside; Penh, enhanced pauses. stimuli (26). Inflammatory cells, including Th2 cells, mast cells, macrophages, lymphocytes, eosinophils and neutrophils, as well as cytokines, particularly IL-4, IL-5 and IL-13, are involved in asthma $(27,28)$. The results of the present study revealed that $\mathrm{G}-\mathrm{Rh} 2$ reverses or prevents several characteristic effects of asthma in model mice. In comparison with OVA-challenged mice, counts of total cells, eosinophils, lymphocytes and neutrophils in BALF were significantly decreased in OVA-challenged mice that were pre-treated with G-Rh2. In patients with asthma, expression levels of Th2 cytokines, including IL-4, IL-5 and IL-13, are increased, and the expression of Th1 cytokines, such as IFN- $\gamma$, is decreased (3). In BAL fluid and lung tissue, G-Rh2 significantly inhibited OVA-induced upregulation of IL-4, IL-5 and IL-13 expression, and inhibited OVA-induced down-regulation of IFN- $\gamma$ expression. Consistent with these biochemical findings, staining with hematoxylin and eosin showed that G-Rh2 treatment ameliorated airway inflammation.

Airway inflammation is regulated by complex interconnected signaling networks, and the precise molecular mechanisms involved in airway inflammation associated with asthma have largely remained to be elucidated. $\mathrm{NF}-\kappa \mathrm{B}$ is present in most cell types and is known to have a critical role in immune and inflammatory responses, including asthma (29-32). In unstimulated cells, NF- $\kappa \mathrm{B}$ is sequestered in the cytoplasm by $\mathrm{I} \kappa \mathrm{B} \alpha$. However, phosphorylation and degradation of $\mathrm{I} \kappa \mathrm{B} \alpha$ allows translocation of $\mathrm{NF}-\kappa \mathrm{B}$ into the nucleus, where it regulates transcription of target genes that encode numerous inflammatory proteins (33), including the cytokines IL-4, IL-5 and IL-13, all of which are closely implicated in the pathogenesis of asthma (34). The role of $\mathrm{NF}-\kappa \mathrm{B}$ in inflammation associated with asthma is corroborated by the present observation that $\mathrm{NF}-\kappa \mathrm{B}$ abundance in nuclear protein extracts from lung tissue was substantially increased in mice exposed to an OVA challenge to induce allergic airway disease. G-Rh2 significantly reduced $\mathrm{I} \kappa \mathrm{B} \alpha$ degradation and translocation of the p 65 subunit of NF- $\kappa \mathrm{B}$ into the nucleus, as well as levels of Th2 cytokines (IL-4, IL-5 and IL-13), in the lungs of OVA-challenged mice. These results indicated that G-Rh2 ameliorated asthmatic symptoms by inhibiting NF- $\kappa \mathrm{B}$ activation.

MAPKs are a group of serine/threonine kinases that include extracellular signal-regulated kinases (ERKs), c-Jun N-terminal kinases (JNKs) and p38 MAPK. MAPKs relay signals generated by exogenous and endogenous stimuli to the intracellular space via protein phosphorylation (35-37). The phosphorylation states and/or activities of the ERKs, JNKs and p38 MAPK are upregulated in animal models of asthma $(38,39)$. In addition, recent studies have shown that SB 239063, a potent and selective p38 MAPK inhibitor, significantly inhibited antigen-induced eosinophilia, promoted apoptosis of eosinophils in BAL fluid (40), and reduced antigen-induced airway inflammatory cell infiltration, levels of IL-4, IL-5 and IL-13, mucus hypersecretion and airway AHR (41). Sulfated 20(S)-ginsenoside $\mathrm{Rh} 2$ inhibited the release of lipopolysaccharide-induced pro-inflammatory mediators by blocking signaling through MAPKs and NF- $\kappa$ B in RAW 264.7 cells (42). Consistent with these data, the present study found that phosphorylation of p38 MAPK was markedly increased after OVA inhalation 
and that G-Rh2 significantly decreased phospho-p38 MAPK abundance in lung tissue from OVA-challenged mice. In addition, the results of the present study showed that G-Rh2 reduced allergen-induced airway inflammation, airway AHR, I $\kappa \mathrm{B} \alpha$ degradation and NF- $\kappa \mathrm{B}$ p65 nuclear translocation in OVA-challenged mice. These findings suggested that the modulation of p38 MAPK signaling involving I $\mathrm{B}$ and $\mathrm{NF}-\kappa \mathrm{B}$ are among the underlying molecular mechanisms of the beneficial effects of G-Rh2 in patients with allergic airway disease.

In conclusion, the present study examined the effects of G-Rh2 on allergen-induced airway inflammation and AHR and investigated the roles of p38 MAPK and NF- $\kappa$ B in these inflammatory processes. In OVA-challenged mice, p38 MAPK phosphorylation, $\mathrm{NF}-\kappa \mathrm{B}$ activation, Th2 cytokine levels, airway inflammation and AHR were inhibited by pre-treatment with G-Rh2. Therefore, the inhibitory effects of G-Rh2 on OVA-induced allergic airway inflammation are mediated, at least in part, by its regulation of p38 MAPK/NF- $\mathrm{MB}$ signaling. The present study provided empirical evidence for the molecular basis for the preventive effects of G-Rh2 against allergic airway diseases.

\section{Acknowledgements}

The present study was supported by the Natural Science Foundation of China (nos. 81260665 and 81160176), the Project of Research \& Innovation of Jilin Youth Leader and Team (no. 20140519013JH) and the Natural Science Research Foundation of Jilin Province for Sciences and Technology (no. 201215235).

\section{References}

1. Kay AB: Asthma and inflammation. J Allergy Clin Immunol 87: 893-910, 1991.

2. Janssen EM, van Oosterhout AJ, van Rensen AJ, van Eden W, Nijkamp FP and Wauben MH: Modulation of Th2 responses by peptide analogues in a murine model of allergic asthma: Amelioration or deterioration of the disease process depends on the Th1 or Th2 skewing characteristics of the therapeutic peptide. J Immunol 164: 580-588, 2000.

3. Mazzarella G, Bianco A, Catena E, De Palma R and Abbate GF: Th1/Th2 lymphocyte polarization in asthma. Allergy 55 (Suppl 61): S6-S9, 2000.

4. Primhak RA and Powell CV: AHR in asthma. Thorax 57: 186, 2002.

5. Robinson DS, Hamid Q, Ying S, Tsicopoulos A, Barkans J, Bentley AM, Corrigan C, Durham SR and Kay AB: Predominant TH2-like bronchoalveolar T-lymphocyte population in atopic asthma. N Engl J Med 326: 298-304, 1992.

6. Tournoy KG, Kips JC and Pauwels RA: Is Th1 the solution for Th2 in asthma? Clin Exp Allergy 32: 17-29, 2002.

7. Umetsu DT, McIntire JJ, Akbari O, Macaubas C and DeKruyff RH: Asthma: An epidemic of dysregulated immunity. Nat Immunol 3: 715-720, 2002.

8. Bao Z, Guan S, Cheng C, Wu S, Wong SH, Kemeny DM, Leung BP and Wong WS: A novel antiinflammatory role for andrographolide in asthma via inhibition of the nuclear factor-kappaB pathway. Am J Respir Crit Care Med 179: 657-665, 2009.

9. Janssen-Heininger YM, Poynter ME, Aesif SW, Pantano C Ather JL, Reynaert NL, Ckless K, Anathy V, van der Velden J, Irvin CG and van der Vliet A: Nuclear factor kappaB airway epithelium and asthma: Avenues for redox control. Proc Am Thorac Soc 6: 249-255, 2009.

10. Xu S, Xu Y, Zhang Z, Ni W and Chen S: Effect of nuclear factor-kappaB on airway remodeling in asthmatic rats. J Huazhong Univ Sci Technolog Med Sci 24: 13-18, 2004.
11. Schieven GL: The biology of p38 kinase: A central role in inflammation. Curr Top Med Chem 5: 921-928, 2005.

12. Fu J, Meng X, He J and Gu J: Inhibition of inflammation by a p38 MAP kinase targeted cell permeable peptide. Med Chem 4: 597-604, 2008

13. Saatian B, Zhao Y, He D, Georas SN, Watkins T, Spannhake EW and Natarajan V: Transcriptional regulation of lysophosphatidic acid-induced interleukin- 8 expression and secretion by $\mathrm{p} 38$ MAPK and JNK in human bronchial epithelial cells Biochem J 393: 657-668, 2006.

14. Saccani S, Pantano S and Natoli G: p38-Dependent marking of inflammatory genes for increased NF-kappa B recruitment. Nat Immunol 3: 69-75, 2002.

15. Woo CH, Lim JH and Kim JH: Lipopolysaccharide induces matrix metalloproteinase-9 expression via a mitochondrial reactive oxygen species-p38 kinase-activator protein-1 pathway in Raw 2647 cells. J Immunol 173: 6973-6980, 2004.

16. Park HM, Kim SJ, Kim JS and Kang HS: Reactive oxygen species mediated ginsenoside $\mathrm{Rg} 3$-and Rh2-induced apoptosis in hepatoma cells through mitochondrial signaling pathways. Food Chem Toxicol 50: 2736-2741, 2012.

17. Chan SW: Panax ginseng Rhodiola rosea and Schisandra chinensis. Int J Food Sci Nutr 63 (Suppl 1): S75-S81, 2012.

18. Jin YH, Yim H, Park JH and Lee SK: Cdk2 activity is associated with depolarization of mitochondrial membrane potential during apoptosis. Biochem Biophys Res Commun 305: 974-980, 2003.

19. Kaneko H and Nakanishi K: Proof of the mysterious efficacy of ginseng: Basic and clinical trials: Clinical effects of medical ginseng korean red ginseng: Specifically its anti-stress action for prevention of disease. J Pharmacol Sci 95: 158-162, 2004.

20. Cheng Y, Shen LH and Zhang JT: Anti-amnestic and anti-aging effects of ginsenoside Rg1 and Rb1 and its mechanism of action. Acta Pharmacol Sin 26: 143-149, 2005.

21. Su JH, Xu JH and Wang ZL: Improving enzymatic production of ginsenoside Rh2 from Rg3 by using nonionic surfactant. Appl Biochem Biotechnol 160: 1116-1123, 2010.

22. Li B, Zhao J, Wang CZ, Searle J, He TC, Yuan CS and Du W: Ginsenoside Rh2 induces apoptosis and paraptosis-like cell death in colorectal cancer cells through activation of p53. Cancer Lett 301: 185-192, 2011.

23. Fei XF, Wang BX, Tashiro S, Li TJ, Ma JS and Ikejima T: Apoptotic effects of ginsenoside $\mathrm{Rh} 2$ on human malignant melanoma A375-S2 cells. Acta Pharmacol Sin 23: 315-322, 2002.

24. Park JS, Park EM, Kim DH, Jung K, Jung JS, Lee EJ, Hyun JW, Kang JL and Kim HS: Anti-inflammatory mechanism of ginseng saponins in activated microglia. J Neuroimmunol 209: 40-49, 2009.

25. Choi IW, Kim DK, Ko HM and Lee HK: Administration of antisense phosphorothioate oligonucleotide to the p65 subunit of NF-kappaB inhibits established asthmatic reaction in mice Int Immunopharmacol 4: 1817-1828, 2004.

26. Bousquet J, Jeffery PK, Busse WW, Johnson M and Vignola AM: Asthma From bronchoconstriction to airways inflammation and remodeling. Am J Respir Crit Care Med 161: 1720-1745, 2000.

27. Wegmann M: Th2 cells as targets for therapeutic intervention in allergic bronchial asthma. Expert Rev Mol Diagn 9: 85-100, 2009.

28. Holt PG and Sly PD: Th2 cytokines in the asthma late-phase response. Lancet 370: 1396-1398, 2007.

29. Siebenlist U, Franzoso G and Brown K: Structure regulation and function of NF-kappa B. Ann Rev Cell Biol 10:405-455, 1994.

30. Baeuerle PA and Baltimore D: NF-kappa B: Ten years after. Cell 87:13-20, 1996.

31. Baldwin AS Jr: The NF-kappa B and I kappa B proteins: New discoveries and insights. Ann Rev Immunol 14: 649-683, 1996.

32. Barnes PJ: Nuclear factor-kappa B. Int J Biochem Cell Biol 29: 867-870, 1997.

33. Ray A, Siegel MD, Prefontaine KE and Ray P: Anti-inflammation: Direct physical association and functional antagonism between transcription factor $\mathrm{NF}-\kappa \mathrm{B}$ and the glucocorticoid receptor. Chest 107 (Suppl 3): S139, 1995.

34. Imanifooladi AA, Yazdani S and Nourani MR: The role of nuclear factor-kappaB in inflammatory lung disease. Inflamm Allergy Drug Targets 9: 197-205, 2010.

35. Schaeffer HJ and Weber MJ: Mitogen-activated protein kinases: Specific messages from ubiquitous messengers. Mol Cell Biol 19: 2435-2444, 1999. 
36. Davis RJ: Signal transduction by the JNK group of MAP kinases. Cell 103: 239-252, 2000.

37. Han $\mathrm{J}$ and Ulevitch RJ: Emerging targets for anti-inflammatory therapy. Nat Cell Biol 1: E39-E40, 1999.

38. Kumar A, Lnu S, Malya R, Barron D, Moore J, Corry DB and Boriek AM: Mechanical stretch activates nuclear factor-kappaB activator protein-1 and mitogen-activated protein kinases in lung parenchyma: Implications in asthma. FASEB J 17: 1800-1811, 2003.

39. Taube C, Nick JA, Siegmund B, Duez C, Takeda K, Rha YH, Park JW, Joetham A, Poch K, Dakhama A, et al: Inhibition of early airway neutrophilia does not affect development of airway hyperresponsiveness. Am J Respir Cell Mol Biol 30: 837-843, 2004.
40. Underwood DC, Osborn RR, Kotzer CJ, Adams JL, Lee JC, Webb EF, Carpenter DC, Bochnowicz S, Thomas HC, Hay DW and Griswold DE: SB 239063 a potent p38 MAP kinase inhibitor reduces inflammatory cytokine production airways eosinophil infiltration and persistence. J Pharmacol Exp Ther 293: 281-288, 2000.

41. Duan W, Chan JH, McKay K, Crosby JR, Choo HH, Leung BP, Karras JG and Wong WS: Inhaled p38alpha mitogen-activated protein kinase antisense oligonucleotide attenuates asthma in mice. Am J Respir Crit Care Med 171: 571-578, 2005.

42. Yi PF, Bi WY, Shen HQ, Wei Q, Zhang LY, Dong HB, Bai HL, Zhang C, Song Z, Qin QQ, et al: Inhibitory effects of sulfated 20(S)-ginsenoside Rh2 on the release of pro-inflammatory mediators in LPS-induced RAW 264.7 cells. Eur J Pharmacol 712 60-66, 2013. 